\title{
En torno de la ubicación de la fortaleza islámica de Qalașat: la importancia económica y estratégica del río Júcar
}

\author{
Francisco Franco SÁNCHEZ *
}

\section{INTRODUCCIÓN}

Los llanos albacetenses han tenido desde los primeros tiempos históricos una gran importancia vial y, por ende, estratégica. Su particular ubicación y su orografía les han hecho obligado paso cuando se desea acudir a otros tantos lugares peninsulares. Las abundantes e importantes vías romanas en ellos trazadas den viva fe de esta importancia geopolítica y vial. También en las épocas visigoda e islámica su utilidad vial no fue menor ${ }^{1}$.

* UNED. Dept. Ha Medieval.

- La pervivencia del uso de las vías romanas en el período islámico y el trazado de los caminos más utilizados por los musulmanes han sido estudiados en numerosos trabajos por F. HeRnÁndez GimÉnEZ. La mayor parte de ellos han sido publicados en la revista «AlAndalus". Entre ellos destacamos especialmente "Los caminos de Córdoba hacia el noroeste en época musulmana", A/-Andalus, Madrid-Granada, XXXII/1, 1967, pp. 37-123 y la segunda parte del mismo artículo en el vol. XXXII/2, 1967, pp. 278-358. Otro trabajo modélico al respecto es el de L. TORRES BaLbAS: “La Vía Augusta y el arrecife musulmán", AlAndalus, Madrid-Granada, XXIV, 1959, pp. 441-448. M. ${ }^{a}$ J. RuBIERA ha estudiado las vias islámicas de la zona levantina; más concretamente las rutas que llegaban a Denia (1985 al y la calzada romano-medieval del río Vinalopó 1985 b). 
Como ha puesto de relieve la Dra. María Jesús Rubiera en su estudio sobre el tramo de la Vía Augusta que discurría por el valle del río Vinalopó (Alicante) (Rubiera, 1985 b), los árabes siguieron en las rutas de su conquista estos magníficos caminos que les legaron romanos y visigodos. En contra de la opinión de P. Sillieres (1977, pág. 31, rectificada en 1982) sostiene con numerosos argumentos la continuación del uso a lo largo de toda la época islámica de la buena red viaria legada por los romanos en la Mancha oriental.

Los musulmanes modificarán el trazado de algunos tramos de las vias preexistentes en función de la nueva situación geopolítica hispana. Como causa y consecuencia a la vez de ello, surgirán nuevos enclaves poblacionales y nuevos centros económicos; son reflejo de una nueva situación política, económica y social propiciada por la conquista islámica y por el cambio radical en todos los órdenes que este fenómeno acarreó.

En una reciente investigación sobre La red vial y defensisa del NE. de la provincia de Albacete. Su importancia geopolítica en el período islámico pude apercibirme de la importancia no sólo de estas calzadas, sino del citado río como vía económica generadora de un espacio defensivo y económico propio. Hasta ahora se ha resaltado la importancia de las vías de comunicación terrestres, pero únicamente de algunos pocos grandes ríos se ha destacado su uso como vías económicas (además de su uso agricola). En trabajos anteriores ya apuntamos la posibilidad de una función vial y económica del río Segura (Franco, 1987 a, 18-21; 1987 b; 1988 a; 1988 b), aunque con los escasos datos que conocemos todavía no estamos en posición de hacer afirmaciones categóricas. Por contra, en base a las fuentes islámicas sí se puede afirmar que el río Júcar tuvo en el período islámico una funcionalidad económica que ha perdurado hasta el presente siglo.

\section{LA QALAȘA ${ }^{\top}$ DE AL-IDRĪSī}

Entre los textos árabes más importantes para el conocimiento de la Mancha oriental y, más concretamente, del alto Júcar, están los itinerarios militares referidos por los cronistas musulmanes. El primero cronológicamente es el Muqtabis, en el que Ibn Hayyān habla de la campaña que 'Abd Al-Raḥmān III emprendió el año 935 contra los rebeldes de 
Zaragoza ${ }^{2}$. Afirma el cronista cordobés que el ejército califal vadeó el Júcar por Qanțarat Turruš (hoy Puente Torres, traducción literal del topónimo), pero no especifica más, ni menciona ningún dato más sobre el lugar exacto o población cercana alguna, a excepción de Chinchilla.

Ibn Șāhib Al-Ṣalā, cronista del s. XII, en su Al Mann bi-l-lmāma (ed. árabe de At-Tāzī, 1964, pp. 487-513) narra el itinerario de la expedición del califa almohade Abū Ya'qūb Yūsuf en 1172 contra las importantes fortalezas de Vilches, Alcaraz y Huete. En el relato de la Campaña de Huete Ibn Șāhib Al-Șalā refiere que la ruta del califa almohade y su numeroso ejército pasó desde las llanuras albacetenses hasta "el río de Alcira (el Júcar) y bebió de él la gente y las acémilas y los ganados hasta saciarse; y descansar allí el miércoles siguiente. El jueves partió y acampó sobre el Júcar a causa del agua para la bebida de los soldados" (A. Huici Miranda, 1969, 206-207; 1970, pp. 171-182). La única referencia al río o su entorno alude al aprovisionamiento de agua para las huestes del califa en el tórrido julio albacetense.

Poco aportan, por tanto, los datos de estos dos conocidos itinerarios (más fecundos en otro tipo de informaciones). Mucho más esclarecedora es la noticia que nos proporciona el geógrafo del siglo XII Al-Idrīsī. En su Kitāb Ruyyār (ed. 1974) hace una descripción de la Península lbérica y, aunque no se trata de un itinerario, como los anteriores, menciona un topónimo desconocido y alude claramente a la importancia económica y geopolítica del río Júcar. Traducimos directamente del texto árabe (AlIdrisī, 1974, p. 44, trad. pp. 185-186):

"Chinchilla es una villa mediana, defendida por un castillo, y rodeada de huertos. Se fabrican allí tapices de lana, que no podrán imitarse, circunstancia que depende de la calidad del aire y de las aguas. Las mujeres son hermosas e inteligentes.

De allí a Cuenca, 80 jornadas.

Cuenca...

De Cuenca a Qalașat, al oriente, 3 jornadas.

Qalașa' es un castillo (hișn) inexpugnable fundando al otro lado de las numerosas montañas, donde crece innumerable arbolado de conífe-

2 Ed. árabe de P. Chalmeta; F. CorRiente y M. SOBH, 1979, p. 358-359, 242-243; trad. castellana de M. ${ }^{a}$ J. VIGUERA y F. CORRIENTE, 1981, pp. 268-269. M. ${ }^{a}$ J. RUBIERA (1986 b) y J. ZANÓN (1986) han estudiado este itinerario, resaltando la primera la persistencia en el uso de las vías romanas durante la época islámica. No siempre los itinerarios que siguieron los ejércitos islámicos discurrieron estrictamente a lo largo de las vías existentes. 
ras (pinos). Se cortan los maderos y son transportados por agua y conducidos hasta Denia y Valencia. Estas maderas van por el río de Qalașa' hacia Alcira y desde allí hacia el castillo (hișn) de Cullera, donde los descargan al mar. Se les embarca y se les lleva a Denia; en ella se construyen grandes navíos y pequeños barcos. Los maderos gruesos se conducen a Valencia, y se envían para la construcción y las viviendas.

De Qalașa a Santa María (de Albarracín), 3 jornadas.

De Qalașa ${ }^{t}$ a Alpuente, la misma distancia...».

La referencia al lugar fortificado de Qalașat, Quelaça o Quelaza, nos informa sobre la importancia del alto Júcar ( $y$ de todo su curso, en general). Diversas opiniones se han vertido sobre la ubicación del hișn Qalașa . Bosch afirma que estaría en la confluencia de los ríos Guadazaón y Cabriel (Al-Idrīīi, p. 243), mientras que Saavedra (Al-Idrïsī, p. 107) la sitúa en el término de Iniesta, provincia de Cuenca (aunque estaría demasiado lejos de cualquier río...); según L. Torres Balbas (1957), aunque no aporta argumentos muy explícitos, Qalașa ${ }^{t}$ estuvo ubicada en el cerro de la Horca, al otro lado del curso fluvial y justo enfrente de la actual población de Alcalá de Júcar.

Deduciendo de los escuetos datos que proporciona Al-Idrīsi, Quelaça debería estar en la ribera del Júcar o del Cabriel, puesto que la describe como un lugar fortificado sobre un río y detrás de las montañas, pobladas de bosques de pinos (alusión a las montañas de la Serranía de Cuenca y a los bosques del NE albacetenses). No es posible identificar Qalașa ${ }^{t}$ de Al-Idrisi con las actuales fortificaciones de Jorquera o Alcalá de Júcar puesto que, aunque sus topónimos son de origen árabe, las primeras noticias que las mencionan son de origen cristiano y datan del siglo XIII, cuando la conquista ha rebajado sus fronteras hasta la línea del Júcar. Concretamente, el primer dato explícito que tenemos de esta zona es de 1211 y viene recogido en la Primera Crónica General, aludiendo a la toma por Alfonso VIII de Alarcón, Jorquera y Alcalá de Júcar ${ }^{3}$. Después de Al-Idrīīi, no hay ninguna noticia posterior sobre Qalașa'; tampoco otras

${ }^{3}$ Tras cruzar el estrecho el gran ejército almohade en mayo de 1211 y apoderarse de Dueñas y Salvatierra, el rey castellano Alfonso VIII concentró sus tropas y acudió, en unión a su hijo Fernando, a reforzar la frontera del Júcar. Trasladó la corte a Alarcón; desde allí, siguiendo el curso fluvial, atacó las tierras del sur del río. La muerte de su hijo en octubre y la entrevista en Cuenca con Pedro li de Aragón le frenaron un cierto tiempo. En noviembre, buscando el remedio a la aflicción por la muerte de su hijo, según relatan las crónicas, hace una nueva incursión en las comarcas del Júcar albacetense, apoderándose en menos de quince días, de los castillos de Garadén, Alcalá de Júcar y Jorquera. La Primera Crónica General (R. Menéndez Pidal/D. Catalán, 1977, p. 688) lo refiere de este modo: "... fuit ad 
anteriores al s. XIII de Jorquera o Alcalá de Júcar, aunque la arqueología demuestra claramente su existencia antes del s. XIII (Franco, 1987 b, 3444). Hasta que unas excavaciones arqueológicas puedan demostrarlo, pensamos que la falta de noticias sobra Qalașa ${ }^{t}$ posteriores al s. XII es indicio de la desaparición de la fortificación y del topónimo después de esta fecha.

Por el contrario, son de gran interés los abundantes restos de un despoblado que se encuentra en el cerro de la Horca, al otro lado del cauce del Júcar y enfrente de la actual población. El yacimiento está a un nivel mucho más elevado que Alcalá, por lo que desde él se dominaría visualmente no sólo el valle inmediato, sino también los terrenos del llano hacia el sur de su posición. No sabemos que se haya hecho estudio arqueológico alguno sobre el yacimiento del cerro de la Horca.

Coincidiendo con el criterio de L. Torres Balbas, creemos que el hișn Qalașa ${ }^{t}$ estaría ubicado enfrente de Alcalá, dominando el curso fluvial del Júcar y detrás de las montañas (tanto las de Cuenca, como de las más inmediatas de la zona de Villatoya hacia Utiel y Requena), en el llamado cerro de la Horca; está enclavado éste en la parte exterior o derecha del meandro que hace el Júcar al pasar por la localidad actual de Alcalá de Júcar (que quedaría enfrente del citado cerro, en el interior o ribera izquierda del meandro fluvial). Corrobora esta localización la afirmación hecha a finales del siglo pasado por Pascual Madoz, quien confirma que «en el cerro de la Horca, situado en la parte superior norte de la población se advierten las ruinas de otro pueblo que debió ser considerable, cuyo nombre y demás circunstancias no han llegado hasta nuestra noticia» $(1845,1$, p. 373, noticia recogida también por J. Roa, 1894, II, 214).

La importancia de Qalașa queda indicada, según Al-Idrīsī, por sus relaciones viales: con Cuenca, de la que está a tres jornadas, con Santa María de Albarracín, de la que dista tres jornadas, con Alpuente, también tres jornadas; fluviales por el "río de Qalașa" ", hacia Alcira y el fuerte de Cullera. Estaba, por tanto, situada en un nudo de caminos que redistribuía las rutas en él confluentes desde el sur (el "Camino de Aníbal»,

castrum quod dicitur Alarcon et ibidem, dimissis uxore et filia, cum paucis militibus et hominibus quarundam uillarom et domesticis suis, cepti infra XV dies nobile castrum Xorquera, quod inexpugnabile uidebatur, et castrum de Alcala et las Cuevas de Garaden, que omnia muniuit armis et hominibus, et sic cum gaudio reuersus est in terram suam». Tras esta campaña retornó el 29 de noviembre de 1211 a Alarcón (A. HuICI MiRANDA, 1970, III, p. 210; A. Pretel, 1986, pp. 79-81; Franco, 1987 b, 26-33. 
Chinchilla y Almansa) hacia Cuenca, Albarracin y Alpuente. Pero su importancia le venía esencialmente de ser lugar de control del paso de las maderas de los bosques de Cuenca; éstas eran conducidas por la vía fluvial hacia Qalașat, Alcira y Cullera. La madera de los bosques conquenses era la materia prima básica para dos actividades esenciales: para la construcción naval y para la «industria» de la construcción de Valencia. El lugar de Qalașa ${ }^{t}$ tenía, por tanto, una esencial función estratégica y militar para el estado y económica para su cora de Valencia. Por ello debió ser cabeza de un espacio defensivo para la vigilancia de esta finalidad vital: la conducción de maderas por vía fluvial.

Desconocemos la razón de la rápida desaparición de la fortificación y del topónimo. Posiblemente la dinámica de la conquista cristiana acabó con este enclave a principios del siglo XIII; tras esta destrucción (o pérdida de su funcionalidad), se encastillarian de nuevo en el picacho donde actualmente está la fortaleza de Alcalá, perdiéndose el topónimo. De todos modos, las fuentes no nos dicen nada al respecto. Sería necesaria alguna campaña de excavaciones para que nos aclarara estas incógnitas. Pero la importancia de las informaciones que nos transmite la Primera Crónica General es muy grande, ya que es primer texto que nos menciona los castillos existentes en la zona y también nos da una idea de la importancia geopolítica y vial del Júcar ${ }^{4}$.

\section{EL CONTROL VIAL}

De las diversas rutas de comunicación que Qalașa controlaba quizá la más importante fuera la vía fluvial. Atestiguada su utilización en el siglo XII por la referencia de Al-Idrīīi, pensamos que su uso se remontaría a mucho antes. Su finalidad esencial sería más el transporte de maderas que el de personas (aunque nada impide pensar lo contrario). Posiblemente también se utilizó la vía íluvial para el traslado de mercancías por

${ }^{4}$ Con el control de estos castrum de Xorquera, castrum de Alcalá y de Garadén los castellanos dominarán una franja fluvial geopolíticamente esencial: les permitió cortar las vías que comunicaban el norte de Albacete con el sur de Cuenca; pueden desplazarse fácilmente a lo largo del curso fluvial hacia la frontera valenciana y los llanos albaceteños, y cortan todas las comunicaciones transversales que permitía el río, además de impedir el tráfico maderero (Franco, 1987 b, 27-31). 
medio de balsas de bajo calado, la presencia del topónimo Caserío de los Malecones en las inmediaciones de Alcozarejos parece abundar en esta idea.

El valle del Júcar también sería utilizado en diversa medida como un camino terrestre paralelo al fluvial. La presencia de carriladas de carretas apunta la existencia de una calzada romano-medieval a lo largo del trazado del Júcar desde Valdeganga (Franco, 1987 b, 47). La vía enlazaría Chinchilla por el área del Júcar con la importante comarca de Caudete de las Fuentes, Requena y Utiel. Así para ir de Chinchilla a Requena se pasaría a $\rightarrow$ La Losilla $\rightarrow$ cerca de Tinajeros $\rightarrow$ Valdeganga $\rightarrow$ Puente Torres $\rightarrow$ Alcozarejos (al-qașr $=$ castillo, o parador, posada [Rubiera, 1987, 81] $\rightarrow$ Calzada de Vergara $\rightarrow$ castillo de Jorquera $\rightarrow$ tramo de calzada hallado cerca de La Recueja $\rightarrow$ hasta Qalașa'/Alcalá (alqala $=$ la fortaleza) de Júcar $\rightarrow$ se saldría del valle en dirección a Zulema $\rightarrow$ Albora $\rightarrow$ Villatoya $\rightarrow$ y atravesando los espesos bosques de la zona hasta Caudete ${ }^{5}$.

En época romana iba directamente la ruta hacia Caudete de las Fuentes. En el siglo $x$ seguira 'Abd Al-Rahmân III precisamente hasta la Torre de Caudete, por el camino más directo hacia el norte. Desde ésta se podría tomar la dirección hacia Valencia, hacia la montaña de Alpuente y dirección hacia Albarracín. Este dato refuerza nuestra hipótesis acerca de la ubicación de Qalașa ${ }^{\dagger}$ en el Cerro de La Horca de Alcalá de Júcar, puesto que además de cumplirse el hecho fluvial se cumple en este enclave la circunstancia vial de ser camino hacia Albarracin y Alpuente (aunque Al-Idrīsī no mencione la dirección hacia Valencia).

La calzada en su tramo paralelo al río comunicaba las diferentes localidades de esta vega albacetense y unía los diversos puntos del sistema defensivo de cuevas (Franco, 1987 b, 28-32 y 37-41), torres y castillos. Difícilmente continuaría como ruta terrestre río abajo después de

${ }^{5}$ En el siglo pasado se lamenta P. MADOz de que estuviera roto el paso del Cabriel en el término de Alborea "sobre todo para Requena y Valencia, lo cual ofrecería grandes ventajas por ser la salida principal de los frutos agrícolas" de esta rica zona del Júcar albacetense. De nuevo reincide en la idea al hablar de Alcalá de Júcar, porque «el paso del río (Júcar por Alcalá) lo es también (peligroso) en todo el espacio que corta su jurisdicción, por haberse inutilizado el camino que se conoce como Puerto Seco, que era el tránsito para Requena y otras villas" (1845, 1, sv., pp. 334 y 373). El tradicional camino hacia Requena fue inutilizado como consecuencia de las guerras carlista y de Independencia. $P$. Madoz se lamenta de que no se hubiera restaurado el paso por el río Cabriel, ya que todos los productos de la rica vega del Júcar tenían sobre todo salida por Requena. 
Alcalá de Júcar, por el gran estrechamiento que sufre el valle fluvial a partir de esta localidad. Lo que sí continúan son los hitos de control situados en el río, como lo atestiguan las ruinas de fortificaciones y torres existentes en Villa de Ves $\rightarrow$ Castillo de don Sancho $\rightarrow$ Cofrentes $\rightarrow$ Cortes de Pallás, etc. siguiendo a lo largo del Júcar por la provincia de Valencia, tal y como lo describió Al-Idrīsī.

\section{LA IMPORTANCIA GEOPOLÍTICA}

Realmente no se puede hablar stricto sensu de la importancia geopolítica de una zona tan concreta como el Júcar albacetense de un modo aislado, puesto que este área geográfica se halla en íntima relación geográfica e histórica con las vecinas del sur de Cuenca y de la montaña valenciana. Precisamente de esta relación le viene su importancia. La misma zona se halla también en el período islámico inserta dentro de unos límites administrativos concretos (esencialmente en la cora de Valencia, y luego la taifa de Denia) que hay que tomar en consideración.

Por ello, la importancia geopolítica de la línea del Júcar albacetense le viene esencialmente conferida por haber sido un eje vial, económico y estratégico en el período islámico. La importancia vial ha quedado explicada en el anterior epígrafe; el control de los caminos era esencial económicamente (para permitir unas buenas relaciones comerciales) y militarmente. Las dos menciones más importantes y explícitas de las fuentes islámicas inciden en este apartado de la vialidad.

Pero si a esta necesidad de control vial se le une el hecho de que por el Júcar y su afluente, el Cabriel, continuamente bajarian las maderas cortadas en el curso alto de ambos ríos ${ }^{6}$ (en las sierras conquenses) y

${ }^{6}$ Aún a mediados del presente siglo se ha utilizado el cauce fluvial en algunas ocasiones con la misma finalidad de conducir las maderas hacia la provincia de Valencia, aunque con la variante de que en Alcalá de Júcar, por el estrechamiento y peculiaridades de la vega, durante un tramo se transportaban las maderas a lomos de caballerías. Esta función naval explica la presencia aún hoy de un topónimo como el de Caserío los Malecones, inmediato a Alcozarejos (punto 30SXJ2123547 del mapa 766: VALDEGANGA, del Servicio Geográfico Nacional, E.: 1:500:000). 
en la misma zona albacetense ${ }^{7}$, estamos ante una nueva y doble importancia: económica (derivada de su aprovechamiento para la construcción en la importante y populosa ciudad de Valencia) y, sobre todo, estratégica. Como nos informa Al-Idrīsi, en el siglo XII, de estos abastecimientos madereros dependían las atarazanas de Denia; ello equivale a afirmar que dependía la flota que el estado Cordobés, y la Taifa de Denia posteriormente, mantenían en el Mediterráneo.

No es de extrañar la protección defensiva que este espacio del Júcar requirió de los gobernantes islámicos. Sabemos que en el siglo $x$ hay un fuerte reforzamiento de las defensas terrestres y navales en el Sharq AlAndalus frente al peligro fatimí norteafricano. Es entonces cuanto se fortalece la flota califal del Mediterráneo, armada que vigilaba las costas andalusíes entre Almería, Denia y las Baleares (M. Epalza, 1981, 162165 y 1984, 95-96; M. ${ }^{a}$ J. Rubiera, 1985 al. Este reforzamiento naval haría aumentar la importancia tanto de los bosques de las serranías de Cuenca, como de las atarazanas de Denia. La madera era conducida hasta las atarazanas por el Júcar hasta Cullera y de allí a Denia por barco, como nos informa Al-Idrīsĩ.

Posteriormente un gobernante como Muŷāhid de Denia, que tenía sus miras más puestas en el Mediterráneo que en sus vecinos andalusíes, se hará dueño de la armada califal y propiaciará una política de fuerte fomento de la construcción naval en sus atarazanas. Este rey deniense comprenderá muy bien la importancia del llano albacetense: englobó dentro de sus dominios de la taifa de Denia la práctica totalidad de la actual provincia de Albacete (exceptuando el sur), buscando tanto el control del «Camino de Aníbal» hasta Segura de la Sierra (M. J. Rubiera, 1985 a. pp. 15-24), como la seguridad en los aprovisionamientos de madera, que le venían por el Júcar, para sus atarazanas. Por ello no cesa hasta hacerse con esta zona albacetense en la segunda mitad del siglo XI, arrebatándosela a Zuhayr, señor de Tudmîr.

${ }^{7}$ Este área del Júcar albacetense ha sido una región muy frondosa hasta el siglo pasado. Los pinos y los almos han abundado extraordinariamente en su vega y en las zonas inmediatas del llano. Por ello, también ella tradicionalmente ha producido gran abundancia de maderas (J. ROA 1984, II, pp. 197-264; P. MADOz, 1841, 1, p. 335 y 373; 1847, 9, p. $641 ; 1849,15$, p. 272). F. Rodríguez Serres, C. Tolosa Costa, 1986, afirman que hubo un aumento de cultivos en el $\mathrm{s}$. XVIII, consecuencia del auge demográfico de la centuria; es entonces cuando comenzaría el gran retroceso de los bosques de este área albacetense. 
El control militar de las rutas viales será también esencial en el periodo de la conquista cristiana. La mayor parte de las noticias que nos han llegado sobre este área de estudio se remontan a esta época. Cuando el dominio de este nudo vial entre la Mancha y Valencia y entre el llano y las serranías norteñas sea esencial para el control de los desplazamientos militares será cuando aparezca esta zona del NE. de Albacete con nombre propio. En estos momentos priman unas circunstancias bélicas muy diferentes a las generales del anterior período islámico. Durante casi medio siglo (primera noticia de 1182, última de 1224) se lucha por el control de este importante nudo de caminos al norte de Chinchilla y por aislar militarmente al enemigo. Así es como han de entenderse las diversas noticias que nos aportan las Crónicas de la conquista, ya referidas.

Pero, como ha sugerido F. Morales Belda (1980), en la «reconquista' hay que ver una serie de hechos diferentes a los bélicos, aunque paralelos. Este investigador ha resaltado la importancia de las disponibilidades forestales como factor estratétigo a la hora de proporcionar materias primas para la construcción naval. Cuando los musulmanes controlan mayoritariamente estas materias estratégicas es cuando poseen el dominio pleno del mar. Pero en el momento en que los cristianos sobrepasan las serranías conquenses y se hacen con estos recursos militares y estratégicos es cuando pueden permitirse empresas marinas de envergadura. Por ello, en opinión de F. Morales, esta «segunda fase" de la reconquista llevada a cabo por Alfonso VIII de Castilla, con ayuda de Alfonso II de Aragón, a finales del siglo xII supondrá el inicio de la salida al mar del reino castellano en unas condiciones que, en poco tiempo, le darán un gran peso naval. De la importancia de la madera fue plenamente consciente Alfonso VIII, puesto que en las primeras leyes de concesión del Fuero de Cuenca promulgó pena «al extraño o no vecino que en términos de ella cazase, pescase, cortase maderas, sacase leñas, sal, hierro y otro metal' ${ }^{8}$. A partir de este momento la reconquista de los enclaves marinos se acelerará notablemente.

Esta es la importancia intrinseca de la madera como recurso estratégico-militar en la Edad Media, y de la zona de Cuenca-norte de Albacete como una de las reservas más importantes de la Península. Las correrías de los conquistadores castellanos por esta zona, independien-

- A. Gonzalez Palencia: Colección de documentos conquenses, Cuenca, Biblioteca Diocesana, tomo I, 1930, cap. 1. 
temente de la lucha por el control vial, suponen el final de esta «segunda fase" de la conquista cristiana, una vez controladas las serranías conquenses. Tras ella se equilibrará la balanza decididamente en su favor, puesto que pasan a poseer una preminencia naval incontestable en muy pocos años. 


\section{BIBLIOGRAFIA}

AL-IDRīisi: Geografía de España, Valencia, ed. Anubar, 256 pp. 1974. Reproducción de los textos árabes relativos a la Península lbérica anteriormente publicados por R. DozY y $M$. DE GoEJe y de las traducciones de SAAVEDRA y de BLÁzQUEZ.

AT-TĀZī, Abdalhâdî (ed. árabe): Ibn Șāḥib Al-Ṣalā Al-Mann bi-l-Imāma, Beirut, 1964.

P. Chalmeta; F. Corriente; M. Sobh (ed. árabe): Al-Muqtabas V, Madrid, IHAC, 1979.

Mikel de Epalza: «Notas sobre el lingüista lbn Sídah y la historia de Denia y su región en el siglo Xl», Revista de Instituto de Estudios Alicantinos, Alicante, 33, 1981, pp. 161172.

-: «Los beréberes y la arabización del País Valenciano", Quaderns de Filologia. Miscel.lània Sanchis Guarner, València, Universitat, I, 1984, pp. 99-100.

Francisco Franco SÁnchez: Estudio de los espacios urbanos de la ciudad de Orihuela en el período islámico, Alicante, 1987, Universidad, Memoria de Licenciatura en prensa.

-: La red vial y defensiva del área del Júcar albacetense. Su importancia geopolítica en el período islámico, estudio aún inédito presentado como resultado de la investigación llevada a cabo gracias a una Ayuda del Instituto de Estudios 
Albacetenses de la Excma. Diputación Provincial de Albacete, 1987 b.

-: «El espacio del agua en la ciudad de Orihuela en época islámica", Agua y Poblamiento musulmán. Aigüa i poblament musulmà (Simposium de Benissa, abril 1987), Benissa, ed. Ajuntament, pp. 33-53, 1988 al.

-: «Estudio del urbanismo islámico de seis localidades de la Vía Augusta: Sagunto / Xàtiva / Orihuela y Ontinyent / Boicarent / Beneixama», comunicación presentada al Congreso sobre La Ciudad Islámica, Zaragoza, 1-4 diciembre de 1988, (en prensa), 1988 b.

Ambrosio HuICI MIRANDA (trad.): Ibn Șāhị al-Șalā. Al-Mann bi-l-imāma, Valencia, 1969, ed. Anubar, 252 pp.

-: Historia Musulmana de Valencia y su región, Valencia, 1969-70, ed. Ayuntamiento, 3 vols.

Pascual MADOZ: Diccionario geográfico-estadístico-histórico de España y sus posesiones de Ultramar, Madrid, vols. 1, 9 y $15,1945,1947$ y 1949.

R. Menéndez Pidal (ed.); Diego Catalán (est. intr.): Primera Crónica General de España, Madrid, ed. Gredos, 1977.

Francisco MORALES BeLdA: «Papel de las disponibilidades forestales en la reconquista del tráfico marítimo de Al-Andalus mediterráneo", Anuario de Estudios Medievales, Barcelona, CSIC, n. ${ }^{\circ} 10,1980$, pp. 173-185.

Aurelio Pretel Marín: Conquista y primeros intentos de repoblación del territorio albacetense (Del período islámico a la crisis del siglo XIII), Albacete, Instituto de Estudios Albacetenses / CSIC., 1986, 303 pp.

Joaquín Roa y Erostarbe: Crónica de la Provincia de Albacete, Albacete, 2 vols., 1891-94. 
Fernando Rodríguez Serres; Carmen Tolosa Costa: «Alcalá de Júcar: una villa albaceteña en 1752», Al-Basit, Albacete, n. ${ }^{\circ} 19$, junio 1986, pp. 95-133.

María Jesús Rubiera: La Taifa de Denia, Alicante, Instituto de Estudios «Juan Gil Albert», 1985 a, 172 pp.

-: Villena en las calzadas romana y árabe, Alicante, Ayuntamiento de Villena / Universidad de Alicante, 1985 b, 57 pp.

-: Itineraria Arabica Hispana: La Vía Augusta, Memoria de Cátedra Inédita, que agradecemos haya puesto a nuestra disposición, 1986 a.

-: «Los precedentes geopolíticos musulmanes del Señorío de Villena", Actas del Congreso de Historia del Señorio de Villena, Albacete, 25-26 octubre de 1986 (en prensa), 1986 b.

Pierre SILLIÉRES: "Le 'Camino de Aníbal'. Itineraire des gobelets de Vicarello, de Castulo a Saetabis", Mélanges de la Casa de Velázquez, Paris, XIII, 1977, pp. 39-83.

-: «Une grande voie romaine menant a Carthagene: La voie Saltigi-Carthago Nova», Madrider Mittelungen, Madrid, 23, 1982, pp. 252-257.

Leopoldo TORRES BALBÁS: Ciudades yermas hispanomusulmanas, Madrid, 1957.

M. ${ }^{a}$ J. Viguera; F. Corriente (trad.): Ibn Hayyān de Córdoba. Crónica del califa 'Abdarrahmān III An-Nãșir entre los años 912 y 942 (Al-Muqtabas V), Zaragoza, Instituto Hispano-Arabe de Cuitura, 1981, 469 pp.

Jesús ZANÓN: «Un itinerario de Córdoba a Zaragoza en el siglo X», Al-Qantara, Madrid, vol. VII, 1986, pp. 31.52. 